\title{
A New Look at the Emergence of an Agro-Energy Nexus: A Graphical Causal Approach
}

\author{
Dae-Heum Kwon \\ Center for Agro-Food Policy Research, Korea Rural Economic Institute \\ 117-3 Hoegi-ro, Dongdeamun-gu, Seoul, 130-710, Korea \\ Tel: 822-3299-4330Ｅ-mail: daeheum@krei.re.kr
}

Jungho Baek (Corresponding author)

Dept. of Economics, School of Management, University of Alaska Fairbanks

213B Bunnell Building, Fairbanks, AK 99775, United States

Tel: 1-907-474-2754Ｅ-mail: jbaek3@alaska.edu

Won W. Koo

Dept. of Agribusiness and Applied Economics, North Dakota State University

400F Richard H. Barry Hall, Fargo, ND 58102, United States

Tel: 1-701-231-7448Ｅ-mail:won.koo@ndsu.edu

Received: July 27, 2012 Accepted: August 11, 2012

doi:10.5296/ber.v2i2.2154 URL: http://dx.doi.org/10.5296/ber.v2i2.2154

\begin{abstract}
This study examines causal mechanisms linking exchange rates and prices of oil and ethanol to the 2006-08 price surge in corn, soybeans and wheat, as well as identifies the relative importance of the selected factors to the price spikes using the graphical causal method and forecast error variance decomposition (FEVD). Results suggest that the interactions among the crop prices are more important than other causal factors in explaining the price hikes. We also find that significant growth in the use of corn for biofuel production and hence increased corn prices play dominant roles in price setting among the major crops.
\end{abstract}

Keywords: Exchange rates, Food Price, Graphical Causal Method, Price surge 


\section{Introduction}

In the literature of agricultural economics, the sharp hikes in prices for major U.S. crops that is, corn, soybeans and wheat - during 2006-2008 have received considerable attention in recent years. ${ }^{1}$ In addition to numerous studies, briefings, and other materials financed or produced by national and international research institutes and interest groups (e.g., Abbott 2008, Lipsky 2008, Rosegrant 2008, Schept 2008), many scholars have independently studied this issue (e.g., Herndon 2008, Headey and Fan 2008, Baek and Koo 2010).The results from these studies indicate that, among other things, rising energy costs (i.e., crude oil prices), increased demand for biofuel production and the weak U.S. dollar have been the main culprits behind the rapid surge in major crop prices during 2006-2008. Trostle (2008), for example, shows that the downward spiral of the value of the U.S. dollar has helped U.S. major crops more competitive in the world market and exerted upward pressure on prices of those crops through the enhanced foreign demand. He also adds that the phenomenal surge in crude oil price during 2007-08 has resulted in hikes in production costs and thus crop prices. Mitchell (2008) and Park and Fortenbery (2008), on the other hand, find that the rise in crude oil prices has encouraged the rapid expansion of biofuel production in the U.S. under the Energy Security and Independence Act of 2007, thereby pushing up demand for farm commodities (i.e., corn) and prices.

Undoubtedly, previous works have advanced our understanding of the recent episode of crop/food price spikes. Studies that have addressed this issue, however, have mostly relied on descriptive and simulation methods rather than rigorous econometric analysis. In addition, the research focus has typically been on identification of the potential causes/factors driving up the crop/food prices with few studies assessing how such factors are impacting crop prices and by how much. For example, if a change in energy prices (i.e., crude oil price) is the main force driving the crop prices up, then it is appropriate to attribute the price hikes to rising energy costs that significantly raised the production costs. It is thus reasonable to conclude that higher crude oil prices play a key role in determining recent increases in crop prices. On the other hand, if changes in several factors such as exchange rates, energy prices and ethanol demand have all resulted in the crop price increase, then we need to decompose the price effects to determine how significant a specific factor has been and how much can be imputed to each factor. Moreover, since corn is competing with soybeans and wheat for cropland in the U.S., significant growth in the use of corn for biofuel production increases corn prices and the increased prices are likely to motivate farmers to increase corn acreage at the expense of soybeans and wheat, thereby resulting in tight supplies and higher prices of soybeans and wheat (Baek and Koo 2010). It is thus crucial to sort out the causal relationships among the major U.S. crops and incorporate those effects in the analysis. In so doing, we only can measure the dynamic effects of the underlying causal factors on the three different crops accurately.

The objective of this study is to empirically re-examine the 2006-08 price surge in the U.S.

\footnotetext{
${ }^{1}$ Between 2006 and 2008, for example, prices of corn, soybeans and wheat increased by 174\%, 125\%, and 190\%, respectively. Accordingly, the Consumer Price Index for all food (food CPI) increased by 5.5\% between 2007 and 2008, the biggest annual surge since 1990 .
} 
major crops in the dynamic time series framework. Empirical focus is on the assessments of (1) causal mechanisms linking the depreciation of the U.S. dollar, rising energy prices and biofuel demand to the sharp hikes in prices for corn, soybeans and wheat; and (2) the relative importance of the selected factors to the rapid surge in those prices. For a careful analysis, we incorporate dynamic interrelationships among the three crops in our analysis, which can have a substantive impact on estimated results, but has been largely ignored by earlier studies. To achieve the objective, we adopta graphical causal method (i.e., PC algorithm) and the forecast error variance decomposition (FEVD). The PC algorithm is used to inductively infer the contemporaneous causal structures, including sorting out the causal relationships among the three major crops. The FEVD is employed to trace out the relative importance of each causal factor by incorporating all the dynamic interrelationships among the selected variables. It is hoped that, in combination, these multiple steps will lead to more robust empirical findings and contribute to the empirical literature on the recent surge in crop/food prices.

The remainder of this paper is organized as follows. The next section discusses the analytical model linking changes in exchange rates, oil prices and biofuel demand to changes in major U.S. crop prices, as well as the empirical method associated with the PC algorithm and FEVD. The following section describes the dataset used in the analysis and empirical procedure. The last two sections discuss the empirical results, and make some concluding remarks.

\section{The Model}

\subsection{The Links between Crop prices, Exchange rates, Oil Prices, Biofuel Demand}

Since the focus of this study is the explanation of changes in prices for major U.S. crops, following previous studies (e.g., Headey and Fan 2008, Baek and Koo 2010), three factors which are found to be of central importance to influence those prices are selected for the model - that is, exchange rates, crude oil prices and biofuel demand. The reduced-form equations for crop supply and demand are specified as follows:

$$
\begin{aligned}
& Q_{i}^{S}=Q_{i}^{S}\left(P_{c}, P_{s}, P_{w}, P_{o}, X_{i}^{S}\right), \forall i=\text { comn soybeans and wheat } \\
& Q_{c}^{D}=Q_{c}^{D}\left(P_{c}, P_{e}, E R, X_{c}^{D}\right) \\
& Q_{i}^{D}=Q_{i}^{D}\left(P_{i}, E R, X_{i}^{D}\right), \forall i=\text { soybeans and wheat }
\end{aligned}
$$

The supply equations for each crop $\left(Q_{i}^{S}\right)$ are specified as a function of prices of corn $\left(P_{v}\right)$, soybeans $\left(\boldsymbol{P}_{z}\right)$, and wheat $\left(\boldsymbol{P}_{w}\right)$, oil prices $\left(\boldsymbol{P}_{o}\right)$ and crop-specific supply shifters $\left(\boldsymbol{X}_{i}^{s}\right)$. Three prices in the equations represent the linkages among crops, while oil prices capture the cost-push effect of energy price changes on agricultural production costs. The demand equation for corn $\left(Q_{\varepsilon}^{D}\right)$ is specified as a function of corn prices $\left(P_{\sigma}\right)$, ethanol prices $\left(P_{*}\right)$, 
exchange rates $(E R)$ and crop-specific demand shifters $\left(X_{\varepsilon}^{D}\right)$. In equation (2) ethanol prices capture the demand-pull effect of corn-based ethanol production on corn prices. The demand equations for soybeans and wheat are specified as a function of its price, exchange rates and crop-specific shifters. Exchange rates in equations (2) and (3) capture the effects of changes in the foreign demand on crop prices.

The market equilibrium conditions for each crop are then:

$$
P_{i}=P_{i}\left(P_{-i}, P_{e}, P_{o}, E R, X_{i}^{S}, X_{i}^{D}\right)
$$

where $P_{-i}=\left\{P_{c}, P_{s}, P_{w}\right\} \backslash\left\{P_{i}\right\}, \forall i=$ corn, soybeans and wheat. Equation (4) postulates simultaneous systems of equations (SSE)to represent interrelationships among prices of the three crops, exchange rates, and prices of oil and ethanol. Note that ethanol prices are incorporated in the soybean and wheat price equations through its effect on the corn prices.

\subsection{PC Algorithm and Forecast Error Variance Decomposition: A Brief Exposition}

One objective of this study is to examine causal mechanisms linking exchange rates, oil prices and biofuel demand to the sharp hikes in prices of corn, soybeans and wheat. To achieve this goal, we apply the PC algorithm, which is described in detail in Sprites et al. (2000). The PC algorithm starts by forming a completely connected undirected graph. Then, it searches for all the (un) conditional independence patterns among the variables through a gradual increase in the number of conditioned variables. Our test results (based on Fisher's $z$-tests), for example, show that the unconditional independence between corn and oil price residuals, and the independence between wheat (soybeans) and oil price residuals conditional on the soybeans price (corn price and exchange rate) residual(s) cannot be rejected at the $10 \%$ level, suggesting that a shock in oil prices does not directly affect innovations of prices of corn, wheat, and soybeans at contemporaneous time. Finally, causal directions are determined when the selected variables exhibit intransitive pattern of statistical dependencies. Specifically, let A, B and C denote three disjoint subsets of variables in our dataset. We infer contemporaneous causal structures as $A \rightarrow C \leftarrow B$ (unshielded-collider) when (i) the variables $A$ and $B$ are each dependent on a third variable $C$ but are independent of each other ( $A-C-B$ ), and (ii) the two extreme variables $A$ and $B$ that are unconditionally independent become dependent once conditioning on the middle variable $C .{ }^{2}$ The test results, for example, show that wheat (corn) price and exchange rate residuals that are originally unconditional independence become dependence once conditioning on soybean price residual; hence, we empirically infer contemporaneous causal structures among innovations as wheat price $\rightarrow$ soybean price $\leftarrow$ exchange rate (corn price $\rightarrow$ soybean price $\leftarrow$ exchange rate) (Figure 1).

The other objective is to measure the relative contribution of a structural shock in each

\footnotetext{
${ }^{2}$ Such causal interpretation is known as the Berkson's paradox in the statistical literature (Berkson 1946) and the explaining away effect in the artificial intelligence (Kim and Pearl 1983).
} 
variable to fluctuations of its own and other variables. The forecast error variance decomposition (FEVD)is used to investigate this issue. ${ }^{3}$ The FEVD approach starts with a set of dynamic equations of the form as follows:

$Z_{t}=\sum_{l=1}^{L} \Phi_{l} Z_{t-l}+\varepsilon_{t}$

where $Z_{t} \equiv\left[P_{c}, P_{s}, P_{w}, E R, P_{e}, P_{o}\right]$. By successively substituting the lagged dependent variables into the right-hand side of the estimated system, equation (5) can be transformed into a vector moving average (VMA) form as $Z_{t}=\sum_{s=1}^{\infty} \Phi_{s} \cdot \varepsilon_{t-s}=\sum_{s=1}^{\infty} \Phi_{s} \cdot A_{0}^{-1} \cdot u_{t-s}=\sum_{s=1}^{\infty} C_{s} \cdot u_{t-s}$

This VMA form represents $Z_{t}$ as a linear combination of current and past forecast errors. Equation (6) can be viewed as a flexible dynamic approximation to the true but unknown underlying relationships in the structural form equation of $A_{0} \cdot Z_{t}=\sum A_{l} \cdot Z_{t-l}+u_{t}$, in which empirical regularities of all the dynamic interrelationships can be statistically captured in the reduced form equation of $Z_{t}=A_{0}^{-1} \sum A_{l} \cdot Z_{t-l}+\cdot A_{0}^{-1} \cdot u_{t}$. In this respect, the second procedure is to impose the identified contemporaneous causal structures on $A_{0}$ in $\varepsilon_{t}=\cdot A_{0}^{-1} \cdot u_{t}$ to orthogonalize the residuals $\left(\varepsilon_{t}\right)$ into the underlying structural shocks $\left(u_{t}\right)$ such that $\operatorname{Cov}\left(\varepsilon_{t}\right)=A_{0}^{-1} \cdot\left(A_{0}^{-1}\right)^{T}$. Finally, each $(i, j)$ th component of $C_{s}(i, j)=\Phi_{s} \cdot A_{0}^{-1}$ represents the (impulse) response of the $i$ th variable to a structural shock in the $j$ th variable in $s$ period. On the other hand, the $(i, j)$ th component of $\left[C_{s}(i, j)\right]^{2}$ measures the relative contribution of each structural shock in the $j$ th variable to the forecast error variance of $i$ th variable in speriod.

\section{Data and Econometric Procedure}

\subsection{Data}

Weekly data are collected for the period from the first week of July 2006 to the first week of July 2008. The data span is chosen because a plethora of studies indicates a consensus that crop prices surge mainly occurred during the period (e.g., Muhammad and Kebede 2009, Baek and Koo 2010).The U.S. prices of corn, soybeans, wheat and ethanol, and are collected from the Chicago Board of Trade. The exchange rate is the weighted average of the foreign exchange

${ }^{3}$ It is worth mentioning that the FEVD examines the relative strength of each causal factor based on the mutatis mutandis condition (necessary changes having been incorporated) rather than the ceteris paribus condition (all other things being fixed). In other words, the FEVD allows all the variables in the system to dynamically interact each other. 
value of the U.S. dollar against the major currencies and is taken from the Federal Reserve Board. The oil price is obtained from the Department of Energy. All variables are converted to natural logarithms and used throughout.

It is worth mentioning that in this study we have attempted to explain the behavior of major crop prices in the very short-term (July 2006-July 2008) using weekly data. Although this contrasts with previous studies addressing this issue, the use of weekly data should have several advantages. First, it should provide more useful information to decision makers concerned with short-term decisions, well within the span of the yearly crop cycle. Second, it considerably increases the number of observations for a given time period; a time span of a few years yields a sufficiently large sample of weekly observations. Keeping the sample period as short as possible is worthwhile because it decreases the possibility of important qualitative changes in market structure during the period of observation. ${ }^{4}$ Finally, weekly data show much wider fluctuations than annual and monthly averages, thereby increasing the ability of statistical tools to measure the relationships among the selected variables.

\subsection{Econometric Procedure}

Before implementing the graphical causal technique and FEVD, the important specification issue to be addressed is the determination of a correctly specified vector autoregressive model (VAR) in equation (5). In the general VAR system with $n$ variables, if all the variables are stationary, the appropriate modeling strategy is to estimate a (unrestricted) VAR in levels (i.e., equation (5)). If all the variables are all nonstationary $I(1)$ and there is no cointegration at all, then the appropriate model is a VAR in first differences involving no long-run elements. If all the variables are cointegrated, on the other hand, then one can model the system as a vector error-correction model (VECM) (Harris and Sollis 2003).

Table 1. Results of DF-GLS unit root tests

\begin{tabular}{|c|c|c|c|c|}
\hline & \multicolumn{2}{|c|}{ Intercept } & \multicolumn{2}{|c|}{ Intercept and Trend } \\
\hline Variable & Level & Difference & Level & Difference \\
\hline$P_{w}$ & -0.321 & $-4.938 * * *$ & -2.144 & $-5.837 * * *$ \\
\hline$P_{s}$ & 2.052 & $-10.620 * * *$ & -1.590 & $-10.887 * * *$ \\
\hline$P_{c}$ & 2.207 & $-9.892 * * *$ & -0.948 & $-9.836 * * *$ \\
\hline$P_{e}$ & -0.738 & $-7.416 * * *$ & -0.602 & $-8.682 * * *$ \\
\hline$P_{o}$ & -0.396 & $-4.937 * * *$ & -1.530 & $-7.696 * * *$ \\
\hline$E R$ & 0.631 & $-8.627 * * *$ & -1.907 & $-9.857 * * *$ \\
\hline
\end{tabular}

Note: $P_{c}, P_{s}, P_{w}, P_{e}$, and $P_{o}$ represent prices of corn, soybean, wheat, ethanol, and oil, respectively. ER denotes the weighted average of the foreign exchange value of the U.S. dollar against major trading partners. The critical values for the DF-GLS tests are $-2.587,-1.944$, and $-1.615(-3.574,-3.025$, and -2.735$)$ for the specification with intercept term only (intercept with time trend) at the $1 \%, 5 \%$, and $10 \%$ significance level, respectively. $* * *$ denotes rejection of the null hypothesis of a unit root at the $1 \%$ significance level.

\footnotetext{
${ }^{4}$ Structural break in agricultural sector can have a substantive impact on estimated results, but at this moment it is very difficult to determine whether the recent episode of crop price spikes are temporary shocks or fundamental shifts representing a new era in U.S. agriculture (Herndon 2008).
} 
Since time series data are most likely nonstationary $I(1)$ processes, the first step in determining a correctly specified VAR model is to identify such time series properties of the variables (i.e., nonstationarity and cointegration). The presence of a unit root in $Z_{t}$ in equation (5) is first tested using the Dickey-Fuller generalized least squares (DF-GLS) (Elliott et al. 1996). The results show that the null hypothesis of nonstationary cannot be rejected at the 5 percent level for all the level series, but can be rejected for all the first difference series, indicating that all the series are nonstationary and integrated of order one processes (Table 1).

With strong evidence that each of our data series is nonstationary $I$ (1) processes, the cointegration test is undertaken to specify the correct dynamic model - that is, either VAR in first differences or VECM. The approach used in this study is the maximum likelihood estimation method developed by Johansen (1988). The null hypothesis that there are at most $r$ cointegrating vectors is tested using the trace eigenvalue statistics. The results show that the null of no cointegrating vector $(r=0)$ and one cointegration $(r=1)$ can be rejected, but fail to reject the null of two cointegration vectors $(r=2)$ at the 5 percent level (Table 2), indicating that there exist at most two cointegration relationships among the six variables. Hence, the VECM framework that incorporates the short- and long-run interrelationships among the variables is selected for subsequent analysis. It is worth mentioning that we select the VAR lag lengths of two $(k=2)$ as the optimal lag, based on both the AIC and diagnostic tests on the residuals; this model does not reveal any significant departures from serial correlation and homoskedasticity.

Table 2. Results of Johansen cointegration test

\begin{tabular}{|c|c|c|c|l|}
\hline Null Hypothesis & Eigenvalue & Trace Statistics & Critical Value & $p$-Value \\
\hline $\mathrm{r}=0$ & 0.336 & 135.116 & 114.493 & $0.001^{* *}$ \\
\hline $\mathrm{r} \leq 1$ & 0.289 & 92.874 & 86.493 & $0.014^{* *}$ \\
\hline $\mathrm{r} \leq 2$ & 0.237 & 57.689 & 62.473 & 0.117 \\
\hline $\mathrm{r} \leq 3$ & 0.168 & 29.865 & 42.269 & 0.470 \\
\hline $\mathrm{r} \leq 4$ & 0.065 & 10.962 & 25.439 & 0.871 \\
\hline $\mathrm{r} \leq 5$ & 0.038 & 4.003 & 11.903 & 0.722 \\
\hline
\end{tabular}

Note: ** denotes rejection of the null hypothesis at the $5 \%$ significance level.

\section{Empirical Results}

To assess causal mechanisms linking exchange rates, oil prices and biofuel demand to prices for corn, soybeans and wheat, the graphical method is applied to the innovations from our six-variable vector error-correction model (VECM). Figure 1 illustrates the directed graph of the final causal structure and Table 3 gives the coefficient estimates of each causal relation that are all statistically significant at the 5 percent level and have the expected signs. From these findings, we can draw several qualitative causal inferences regarding the recent spikes in major crop prices. First, there indeed exist dynamic interrelationships among the major U.S. crops; that is, a shock in corn prices directly influences wheat and soybean prices, and a 
shock in wheat prices affect soybean prices. Second, a sudden rise in oil prices results in an increase in demand for ethanol and hence ethanol prices. Third, a shock in energy prices tends to be transmitted to the three crops through the causal influence of ethanol prices on corn prices. Finally, a shock in exchange rates negatively affects prices of soybeans and crude oil, given that exchange rate is defined in a way that a decrease reflects a real depreciation of the U.S. dollar against major currencies.

Table 3. Coefficient estimates of contemporaneous causal structure

\begin{tabular}{|c|c|c|c|c|}
\hline Causality & Coefficient & Standard Error & $t$-Statistics & $p$-Value \\
\hline$P_{w} \leftarrow P_{c}$ & 0.535 & 0.095 & 5.606 & $0.000^{* *}$ \\
\hline$P_{s} \leftarrow P_{w}$ & 0.201 & 0.065 & 3.083 & $0.002^{* *}$ \\
\hline$P_{s} \leftarrow P_{c}$ & 0.383 & 0.065 & 5.885 & $0.000^{* *}$ \\
\hline$P_{s} \leftarrow E R$ & -0.869 & 0.397 & -2.192 & $0.028^{* *}$ \\
\hline$P_{c} \leftarrow P_{e}$ & 0.186 & 0.092 & 2.026 & $0.043^{* *}$ \\
\hline$P_{e} \leftarrow P_{o}$ & 0.257 & 0.104 & 2.479 & $0.013^{* *}$ \\
\hline$P_{o} \leftarrow E R$ & -1.179 & 0.528 & -2.232 & $0.026^{* *}$ \\
\hline
\end{tabular}

Note: $* *$ denotes rejection of the null hypothesis of zero coefficient at the $5 \%$ significance level.

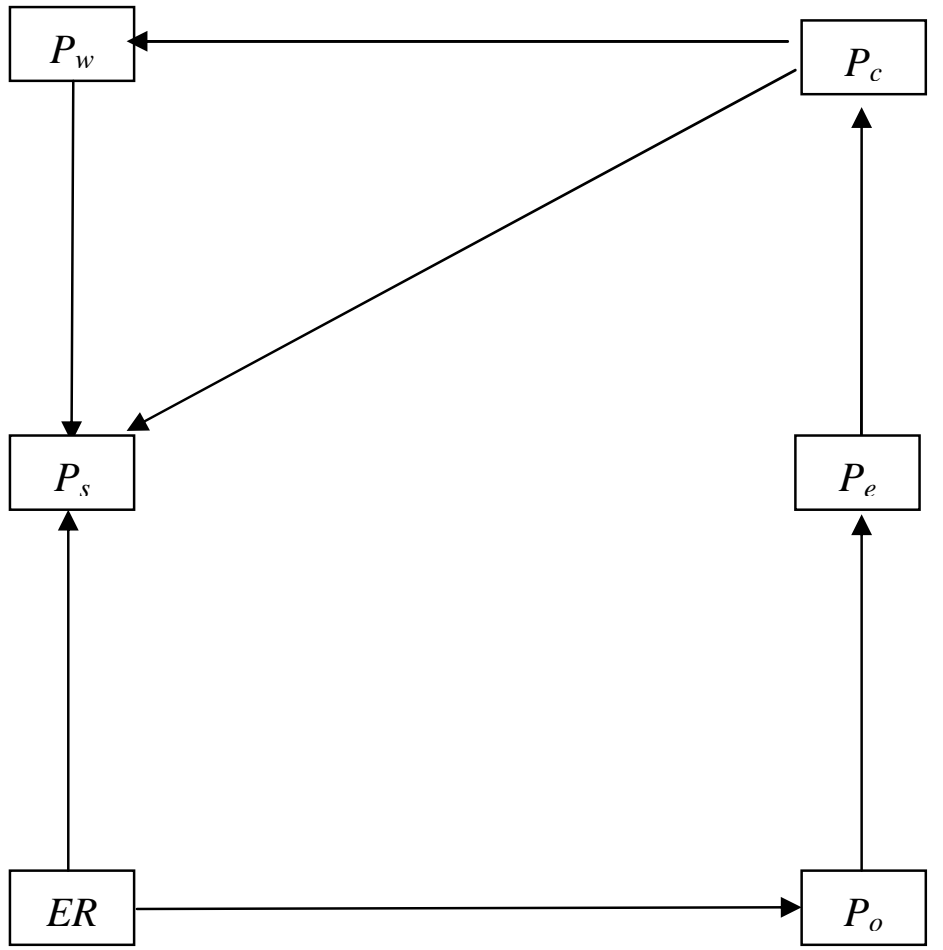

Figure 1. Inferred contemporaneous causal structure

To measure the relative strength of dynamic relationships among the variables, the forecast error variance decomposition (FEVD) is used. Table 4presents the forecast error decomposition associated with prices of corn, soybeans, wheat and ethanol, at horizons of zero, one, four, eight and twelve weeks. One of the key findings of the FEVD is that the interactions among the three crops appear to explain over $85 \%$ of the forecast error variance (FEV) of the three crop prices, implying that interrelationships among the crops are more 
important than other causal factors. This finding further explains why it is crucial to incorporate dynamic interrelationship among the major crops in explaining the recent episode of crop price spikes. In addition, corn prices are found to play a dominant role in price setting among the major crops during 2006-2008. Soybean (wheat) prices, for example, explain only at most $1.91 \%(4.60 \%)$ of the FEV of corn prices, while corn prices account for a maximum of $45.74 \%(31.17 \%)$ of the FEV of soybean (wheat) prices. This finding provides empirical evidence for the following remarks by Herndon (2008); "the primary reason attributed to these record high prices for soybeans and wheat is to "buy back" the 15.3 million acres of land that shifted from other major row crops to corn production in 2007-08."Notice that soybean prices are found to be driven mainly by corn prices, whereas wheat prices are found to be largely determined by soybean prices. Corn prices, for example, explain $45.74 \%(9.52 \%)$ of the FEV of soybean (wheat) prices at 12 weeks, while soybean (corn) prices account for $41.88 \%(9.52 \%)$ of variation in wheat prices at 12 weeks. This substantiates the following observations by Babcock (2008); "the most direct competitor to corn for land is soybeans. ... Wheat acreage will be influenced to some degree by corn prices because of land competition with soybeans and, in some regions, corn."

Another key finding is identification of the existence of the relative strength of each causal factor to fluctuations in crop prices. For example, the contribution of exchange rates to fluctuations in wheat (soybean) prices tends to increase (decrease) from $2.31 \%$ at 1 week $(3.20 \%$ at zero week) to $5.47 \%(0.89 \%)$ at 12 weeks. In addition, the contribution of ethanol prices to corn increase from $2.77 \%$ at zero week to $11.68 \%$ at 12 weeks. Notice that the relative importance of a shock in ethanol prices to corn prices $(2.77 \sim 11.68 \%)$ is larger than the combined contribution of oil prices and exchange rates (at maximum of $2.6 \%$ combined at 12 weeks), implying that ethanol prices play a more important role in influencing fluctuations in corn prices. In fact, U.S. ethanol production in 2008(excluding December)was 199.6 million barrels, up 43\% from 2007. Accordingly, over 20\% of U.S. corn production in 2008 was used in bio-energy production and hence corn prices increased by 174\% between 2007 and 2008 (Muhammad and Kebede 2009).

Finally, the results show that the FEV of ethanol prices explained by its own innovation substantially decreases from $94.45 \%$ at zero week to $15.78 \%$ at 12 weeks, indicating that movement in ethanol prices is highly vulnerable to outside shocks (e.g., changes in prices of crude oil and corn) in the system. The contribution of a shock in oil (corn) prices to ethanol prices, for example, increases from $8.00 \%(6.61 \%)$ at 1 week to $26.21 \%(52.43 \%)$ at 12 weeks. Hence, this finding suggests that high oil prices and relative low corn prices may make corn-based ethanol production more attractive and profitable. As oil (corn) prices decrease (increase), however, future ethanol demand may rely more on the government incentives (e.g., tax credits) as well as renewable fuels mandates that guarantee increased demand in the future (e.g., Energy Policy Act of 2005 and Energy Independence of Security Act of 2007). 
Table 4. Results of forecast error variance decomposition (FEVD)

\begin{tabular}{|c|c|r|r|r|r|r|r|r|r|}
\hline Variable & Step & \multicolumn{10}{|c|}{ By Innovation in } \\
\hline Explained & (weeks) & \multicolumn{1}{|c|}{$\mathrm{Pw}$} & \multicolumn{1}{c|}{ Ps } & \multicolumn{1}{c|}{ Pc } & \multicolumn{1}{c|}{ Pe } & \multicolumn{1}{c|}{ Po } & \multicolumn{1}{l|}{ ER } & \multicolumn{1}{c|}{ Crops } & Factors \\
\hline $\mathrm{Pw}$ & 0 & 75.92 & 0.00 & 24.08 & 0.00 & 0.00 & 0.00 & 100.00 & 0.00 \\
\hline & 1 & 64.68 & 1.27 & 31.17 & 0.54 & 0.03 & 2.31 & 97.13 & 2.87 \\
\hline & 4 & 57.74 & 15.70 & 20.82 & 1.12 & 0.14 & 4.48 & 94.26 & 5.74 \\
\hline & 8 & 48.48 & 32.02 & 12.32 & 1.38 & 0.47 & 5.33 & 92.82 & 7.18 \\
\hline & 12 & 40.95 & 41.88 & 9.52 & 1.43 & 0.75 & 5.47 & 92.35 & 7.65 \\
\hline Ps & 0 & 6.20 & 65.50 & 25.11 & 0.00 & 0.00 & 3.20 & 96.80 & 3.20 \\
\hline & 1 & 3.16 & 68.23 & 26.15 & 0.62 & 0.26 & 1.58 & 97.54 & 2.46 \\
\hline & 4 & 2.32 & 64.54 & 30.84 & 0.49 & 0.82 & 0.99 & 97.70 & 2.30 \\
\hline & 8 & 2.33 & 56.01 & 39.56 & 0.30 & 0.89 & 0.91 & 97.91 & 2.09 \\
\hline & 12 & 2.45 & 49.81 & 45.74 & 0.21 & 0.89 & 0.89 & 98.01 & 1.99 \\
\hline & 0 & 0.00 & 0.00 & 97.23 & 2.77 & 0.00 & 0.00 & 97.23 & 2.77 \\
\hline & 1 & 2.31 & 1.91 & 91.48 & 3.05 & 0.15 & 1.10 & 95.69 & 4.31 \\
\hline & 4 & 3.88 & 1.61 & 86.46 & 6.32 & 0.53 & 1.20 & 91.95 & 8.05 \\
\hline & 8 & 4.47 & 0.91 & 82.60 & 9.77 & 1.29 & 0.96 & 87.97 & 12.03 \\
\hline & 12 & 4.60 & 0.80 & 80.33 & 11.68 & 1.78 & 0.82 & 85.72 & 14.28 \\
\hline & 0 & 0.00 & 0.00 & 0.00 & 94.45 & 5.55 & 0.00 & 0.00 & 100.00 \\
\hline & 1 & 1.03 & 0.39 & 6.61 & 81.65 & 8.00 & 2.31 & 8.03 & 91.97 \\
\hline & 4 & 0.65 & 0.80 & 29.65 & 46.17 & 19.11 & 3.61 & 31.10 & 68.90 \\
\hline & 8 & 1.59 & 0.41 & 45.91 & 24.05 & 24.66 & 3.37 & 47.91 & 52.09 \\
\hline & 12 & 2.24 & 0.24 & 52.43 & 15.78 & 26.21 & 3.10 & 54.91 & 45.09 \\
\hline
\end{tabular}

\section{Concluding Remarks}

The main objective of this study is to empirically re-examine the 2006-08 price surge in the U.S. major crops - corn, soybeans and wheat. Although numerous studies on the issue exist, relatively limited efforts have been made to causal mechanism of selected causal factors to U.S. major crops in the framework of dynamic time series modeling. This study thus has attempted to assess the relative importance of exchange rates, crude oil prices and biofuel demand and causal mechanism of each factor to the sharp hikes in prices for corn, soybeans and wheat using the graphical causal method and forecast error variance decomposition (FEVD).Furthermore, we have paid close attention to incorporate dynamic interrelationships among the three crops in our analysis, which has been ignored by previous studies.

Overall, our results support the proposed hypothesis that there exists dynamic interrelationships among the prices of corn, soybeans and wheat during 2006-08. This explains why it is crucial to incorporate those effects in the analysis in order to understand the recent episode of crop price spikes accurately. Specifically, our findings show that (1) the dynamic interactions among prices of corn, soybeans and wheat seem to be more important than the combined effects of causal factors on those prices; (2) significant growth in the use of corn for biofuel production and increased corn prices play dominant roles in influencing changes in the three crop prices; (3) the effects of biofuel demand on corn prices are more 
significant than the combined effects of oil prices and exchange rates; and (4) fluctuations in ethanol prices heavily rely on changes in oil and corn prices.

\section{References}

Abbott, P. C., Hurt, C., Tyner, W. E. (2008). What's driving food prices? Issue Report, Farm Foundation.

Babcock, B. A. (2008). Fuel subsidies and impact on food prices. Statement before the U.S. Senate Committee on Homeland Security and Government Affairs.

Baek, J., Koo, W. W. (2010). Analyzing factors affecting U.S. food price inflation.Canadian Journal of Agricultural Economics 58(3), 303-320.

Berkson, J. (1946). Limitations of the application of fourfold table analysis to hospital data. Biometrics Bulletin 2,47-53. http://dx.doi.org/10.2307/3002000

Elliot, G., Rothenberg, T. J., Stock, J. H. (1996). Efficient tests for an autoregressive unit root. Econometrica 64(4), 813-836. http://dx.doi.org/10.2307/2171846

Fortenbery, R. T., Park, H. (2008). The effect of ethanol production on the U.S. national corn price. Staff Paper No. 523. Department of Agricultural and Applied Economics, University of Wisconsin-Madison.

Harris, R., Sollis, R. (2003). Applied Time Series Modeling and Forecasting. Chichester: John Wiley and Sons.

Headey, D., Fan, S. (2008). Anatomy of a crisis: the causes and consequences of surging food prices. Agricultural Economics $\quad 39, \quad 375-91$. http://dx.doi.org/10.1111/j.1574-0862.2008.00345.x

Herndon, C. W. (2008). The ethanolization of agriculture and the roles of agricultural economists. Journal of Agricultural and Applied Economics 40(2), 403-14.

Johansen, S. (1988). Statistical analysis of cointegration vectors. Journal of Economics Dynamics and Control 12, 231-54. http://dx.doi.org/10.1016/0165-1889(88)90041-3

Kim, J. H., \& Pearl, J. (1983). A computational model for combined causal and diagnostic reasoning in inference systems. Cognitive Systems Laboratory, University of California, Los Angeles, Technical Report R-25.

Lipsky, J. (2008). Commodity prices and global inflation. Remarks by the First Deputy Managing Director of the IMF at the Council on Foreign Relations. New York City.

Mitchell, D. (2008). A note on rising food prices. Policy Research Working Paper No. 4682. The World Bank, Washington, D.C.

Muhammad, A., Kebede, E. (2009). The emergence of an agro-energy sector: is agricultural importing instability from the oil sector? Choice 24(1), 12-5.

Rosegrant, M. (2008). Biofuels and grain prices: impacts and policy responses. Testimony for 
the U.S. Senate Committee on Homeland Security and Governmental Affairs. Washington, D.C.: International Food Policy Research Institute.

Scnepf, R. (2008). High agricultural commodity prices: what are the issues? CRS Report for Congress. Congressional Research Service, Washington, D.C.

Spirtes, P., Glymour, C., Scheines, R. (2000). Causation, Prediction, and Search, 2nd ed. New York: MIT Press.

Trostle, R. (2008). Global agricultural supply and demand: factors contributing to the recent increase in food commodity prices. ERS Report WRS-0801, Economic Research Service, United State Department of Agriculture.

\section{Copyright Disclaimer}

Copyright reserved by the author(s).

This article is an open-access article distributed under the terms and conditions of the Creative Commons Attribution license (http://creativecommons.org/licenses/by/3.0/). 